\section{Incidence and acceptance of errors in medicine}

\author{
D. Hatch
}

\begin{abstract}
Summary
The limited data that exist concerning the incidence of errors in medicine come mainly from the USA and Australia. These, together with limited data from the UK, suggest that though the incidence is high, relatively few adverse events which harm patients are due serious deficiencies in individual doctors. There is no universally accepted definition of medical error. Organisations such as the airline industry base their philosophy on the acceptance that even highly skilled and competent individuals make mistakes, and design systems to minimise their consequences. Organisations whose approach is to rely on error-free performance, as often appears to be the case in medicine, are bound to fail. The UK government is beginning to attack the latent organisational failures which are almost always found to contribute to adverse outcomes when human errors occur.
\end{abstract}

\section{Introduction}

Lucien Leape, in his review of errors in medicine [1], pointed out that Florence Nightingale gave the medical profession a valuable motto when she wrote in her manuscript Notes on Hospitals in 1863 "Primum non nocere" meaning "most importantly, cause no harm" [2]. In the past, this laudable aim was not difficult to achieve, since the physician had few powerful drugs or techniques at his disposal. The major advances in medicine which have occurred in recent years have not only given doctors the power to confer great benefits on patients, but also the ability to cause great harm. In this context, the human errors to which we are all inevitably prone may have much more serious implications for our patients.

Correspondence:

Professor David Hatch

Institute of Child Health

30 Guilford Street

UK-London WC1N 1EH

\section{Incidence and causation of errors}

Only a small percentage of adverse events which harm patients are due to the serious deficiencies in individual doctors which would bring them before the General Medical Council, the national regulatory body for doctors in the United Kingdom. I have described elsewhere how the GMC now deals with these doctors, and how it plans to ensure that the professional performance of all doctors will in future be regularly assessed so that problems can be addressed at an early stage [3]. This paper addresses the incidence and causes of medical error and the steps that the Government and others, including the GMC, are taking to minimise the risk of harm to patients.

There have been relatively few studies of the incidence of error in health care, and most data come from the United States. In 1964, Schimmel found that $20 \%$ of patients admitted to a university hospital suffered iatrogenic injury, of which 20\% were fatal [4]. Steel, in 1981, found a $36 \%$ incidence of injury related to errors, of which $25 \%$ were serious or life threatening and over $50 \%$ of which were related to the administration of medication [5]. Dearden and Rutherford, in 1985, found that for 58\% of patients with severe trauma in the emergency room there had been serious errors in treatment [6]. In 1991, Bedell estimated that $64 \%$ of cardiac arrests were preventable [7]. Also in 1991, Brennan and Leape from Harvard identified 1133 patients with disabling injuries caused by medical treatment in a randomly selected sample of 30,195 hospital records, an incidence of $3.7 \%$ [8]. Several of these authors noted that many of these preventable deaths were drug related. Nearly $14 \%$ of these were fatal and negligent care was deemed responsible by independent assessors in $28 \%$ of cases. If this incidence is typical of the United States, it suggests that there were in the order of 180,000 iatrogenic deaths per annum in that country. A third of these deaths, equivalent to 1 jumbo jet crash every 2 days, were attributed to grave negligence. The largest number of adverse events were drug related followed by wound infection and technical complications. Many of these, however, were unpredictable and impossible to prevent, such as allergic reactions to drugs to which the patient had no previous known exposure. Some were complications which might have been avoidable, such as bone marrow depression from cytotoxic drugs, and others resulted from errors in administration or monitoring, such as bleeding associated with the use of anticoagulant drugs. The percentage of adverse events due to negligence was highest in relation to diagnostic or therapeutic mishaps, such as failure to diagnose an ectopic pregnancy, and to surgical failures, such as incomplete removal of a disk at laminectomy. 


\section{Figure 1}

The dynamics of accident causation.

The diagram shows a trajectory of accident opportunity penetrating several defensive systems. This results from a complex interaction between latent failures and a variety of local triggering events. It is clear from this figure, however, that the chances of such a trajectory of opportunity finding loopholes in all of the defences at any one time is very small indeed. Reproduced with permission [11].

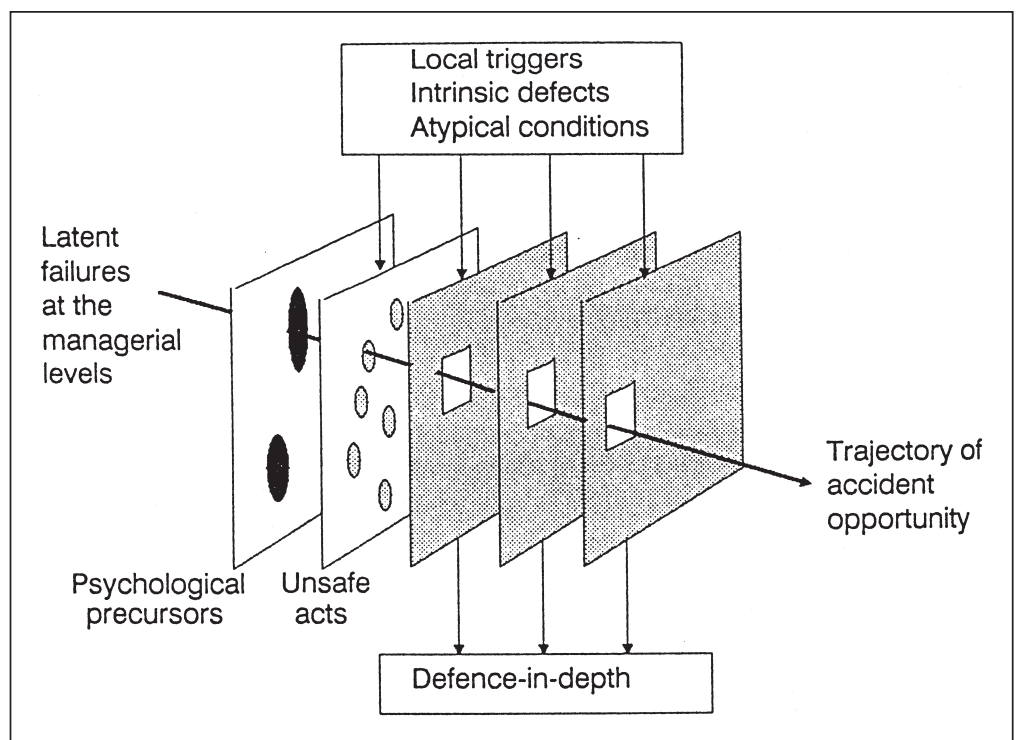

Evidence from the Australian healthcare study suggests an even higher incidence of harm [9]. If either of these data are extrapolated to the National Health Service (NHS) in England, even allowing for differences in health care systems, the estimated number of patients involved is worryingly high. The latest analyses suggest that an estimated 850,000 adverse events might occur each year in the NHS hospital sector, resulting in a $£ 2$ billion direct cost in additional hospital days alone. Around half of these adverse events are thought to be avoidable.

The NHS paid out $£ 400$ million in clinical litigation settlements in 1998/9 and has a potential of around £2.4 billion from existing and expected claims - when analysed many cases of litigation show potentially avoidable causes. There were over 38,000 complaints about all aspects of Family Health Services during 1998/9 and nearly 28,000 written complaints about aspects of treatment in hospitals alone. At least 13 patients have died or been paralysed since 1985 because a drug has been wrongly administered by spinal injection. Around six patients receive mismatched blood transfusions each year. Over 6,600 adverse incidents involving medical devices were reported to the Medical Devices Agency in 1999, including 87 deaths and 345 serious injuries. The costs to the NHS of hospital acquired infections have been estimated at nearly $€ 1$ billion a year, and around $15 \%$ of cases are regarded as preventable.

Experience from the serious incident reporting system run by one of the NHS Executive's Regional Offices suggests that nationally at least 2,500 adverse events occur a year which should be serious enough to register on such systems. There is almost certainly a significant under-reporting of such events.

Given the complex nature of medical practice and the multiplicity of interventions that each patient receives, a high error rate is perhaps not surprising. One study in a medical intensive care unit revealed an average of 1.7 errors per day, per patient, of which $29 \%$ had the potential for serious or fatal injury [10]. However, this must be seen against a background in which the patients were receiving an average of 178 activities per day. The data therefore suggests that hospital personnel were functioning at a $99 \%$ level of proficiency. However, the $1 \%$ failure rate is substantially higher than would be tolerated in other hazardous fields of activity, such as aviation. Deming has pointed out in a written communication quoted by Leape that even $99.9 \%$ efficiency may not be satisfactory, since this would lead to the occurrence of two unsafe plane landings per day at 0'Hare International Airport in Chicago, 16,000 pieces of lost mail and 32,000 bank cheques deducted from the wrong bank account every hour [1]. It is also important to emphasise that not all errors lead to serious outcomes, and it is well known that the vast majority of errors which do not harm patients go unreported. Errors of omission may be just as serious as errors of commission. In the United Kingdom, for example, there has been a seriously low uptake of the use of streptokinase in the early management of acute myocardial infarction despite clear research evidence to indicate its effectiveness in reducing mortality.

In defining the incidence of errors, it is also important to understand what we mean by a medical error. If a radiologist fails to identify a small gallstone in the lower corner of a chest $\mathrm{x}$-ray, should this be regarded as an error? Many radiologists would argue that it should not be, though patients may have a different view point. In developing the GMC's performance procedures, it became clear that there was a well-recognised error rate in reporting of $\mathrm{x}$-rays and histopathological material, even in the best practices. Whilst the cost of reducing this error rate to zero would be prohibitively high, it should surely be a consideration when determining whether an individual doctor has been performing at a seriously deficient level. Equally, not all errors are regarded as equally serious, even though they may cause harm to patients. For example, if a surgeon fails to diagnose acute appendicitis in the presence of clear medical history and physical signs, this would be regarded as a serious mistake. If, on the other hand, a surgeon removes a normal appendix unnecessarily, this is regarded as unremarkable, even though the patient has suffered an unnecessary operation.

James Reason, in the Department of Psychology at the University of Manchester, has been one of the UK's leading researchers in the field of systems failures and error. He studied major disasters such as the Challenger space-flight, the leaks of radiation from the nuclear reactor at Three Mile Island in the USA and Chernobyl, the chemical spillage in the Indian city of Bhopal, the Zeebrugge cross-channel ferry dis- 


\section{Figure 2}

Total cases referred to GMC 1995-2000.

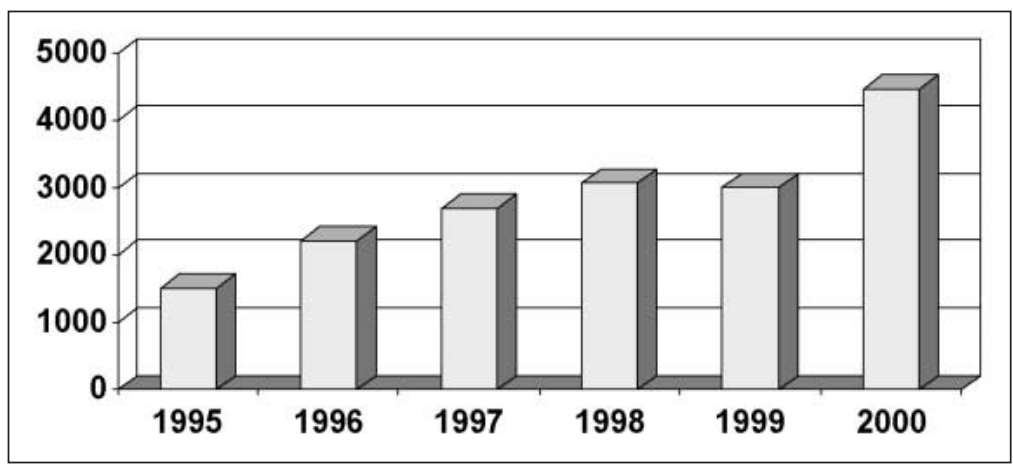

Figure 3

Clinical performance cases referred to the GMC 1997-2000.

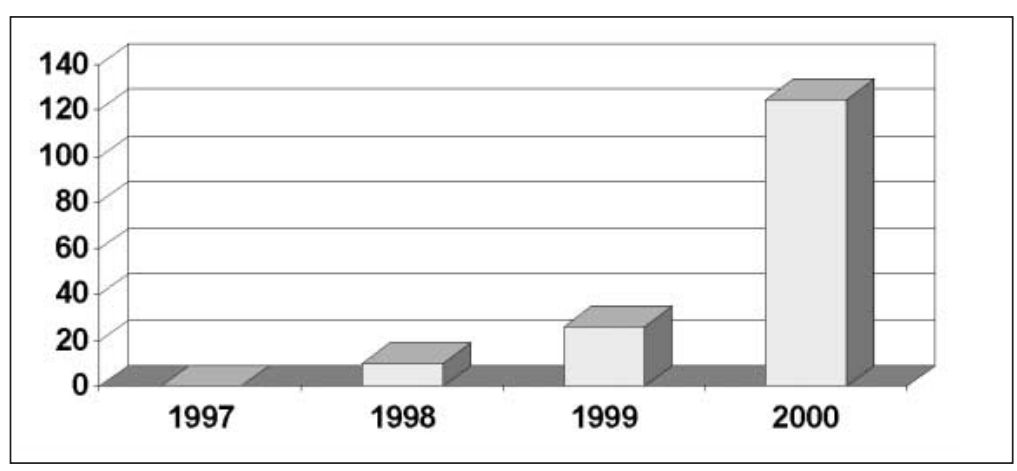

aster and the fire at King's Cross underground station in London. In each case he identified what he called active errors by individuals, the unsafe acts committed by those at the sharp end whose effects are felt almost immediately [11]. They can be slips, lapses, mistakes or procedural violations. They tend to occupy the spotlight in any subsequent investigation. James Reason also however identified in every case latent errors, whose adverse consequences may lie dormant within the system for a long time. He likens these to resident pathogens within the human body, only becoming evident when they combine with other factors to breach the system's defences. They may include fatigue, staff shortages, lack of experience or inadequate equipment. To use another analogy, they are like mosquitoes. If you swat them one by one they will keep on coming. The real remedy is to drain the swamps in which they breed. Latent conditions can result from decisions made by designers, builders, managers and even governments. They are often more difficult to identify and less satisfactory to deal with, since usually no individual can be held accountable.

\section{Management of errors}

There are two ways of viewing human error: the person centred approach, which focuses on the psychological precursors of error, such as inattention, forgetfulness and carelessness. This approach uses methods that attempt to modify the behaviour of individuals, such as written guidelines \&t protocols or else resorts to disciplinary measures. Though this approach may be attractive from managerial and legal perspectives, it has serious disadvantages when applied to health care, since it isolates unsafe acts from their context and makes it very hard to uncover and eliminate predisposing latent errors in the system.

The other approach, the systems approach, follows Reason's "Swiss cheese" model (fig. 1). In a well-managed system there should be several layer of defences separating the hazards from the losses. In reality, there are always holes in the layers; some caused by active failures of individuals and others by latent conditions. Unlike cheese, these holes are continuously opening, closing and changing position. Serious danger only arises when a set of holes opens up to allow a brief window of accident opportunity. The more protective layers there are, the safer the system [12].

It may be helpful to learn from the airline industry's approach to error management. Interestingly, although the error rate in medicine is clearly high, it may not be significantly different from that in aviation. Perrow, in a study of airline cockpit crews in 1984 , observed that human errors or instrument malfunctions occurred on an average of 1 in every 4 minutes during an international flight [13]. The reason that none of these errors led to disaster appeared to be that each event was promptly recognised and corrected, together with the fact that over the years many layers of defences have been built into the system. Pilots are also obliged to submit to an external authority, the air traffic controller, at the most dangerous times of take off and landing and all airlines and pilots are required to comply with the strict safety standards applied by the regulatory body. All near miss mid-air collisions, which are reported to occur more than 5,000 times a year, are automatically logged and investigated. Pilots must undertake performance-testing examinations in a simulator on a regular basis. In short, the airline industry is a superb example of an industry whose basic approach is the acknowledgement that even good individuals will sometimes make mistakes. Such checks and balances as are required to ensure that these mistakes do not lead to adverse outcomes are built into the risk management systems. In medicine, on the other hand, the basic approach continues to be to rely on individuals not to make mistakes, rather than to assume that they will, despite increasing evidence to demonstrate that systems which rely on error-free performance are bound to fail. 
Marc de Leval, a children's cardiac surgeon at Great Ormond Street Children's Hospital in London, has a particular research interest in systems failures and has shown that even small distractions, not on their own very significant, can have a cumulative effect which could influence outcome [14]. An example of how systems failure can lead to tragedy is powerfully illustrated in the Report of the Department of Health's expert group on learning from adverse events in the NHS, published last year under the title "An organisation with a memory" [15]. It describes the sequence of events leading to the death in 1997 of a young boy from maladministration of an anticancer drug, vincristine, which should never be administered intrathecally (table 1).

As I have already indicated, this error has occurred 13 times since 1995, the latest tragedy occurring shortly after the publication of the Department of Health's report. On the other hand, a systems based approach in anaesthesia has reduced the mortality in anaesthesia from $1: 10,000$ to $1: 200,000$ in 10 years. The increasing use of patient simulators may reduce it further.

The current UK government claims that assuring and improving the quality and safety of clinical services is a key theme of its health service modernisation strategy [16]. It has introduced the phrase "Clinical Governance", defined as a "framework through which NHS organisations are accountable for continuously improving the quality of their services and safeguarding high standards of care by creating an environment in which excellence in clinical care will flourish". It sets out a three-pronged approach to quality improvement comprising:

- Clear national quality standards set by a new $\mathrm{Na}$ tional Institute for Clinical Excellence promoting clinical and cost-effectiveness through guidance and audit and developing a programme of evidence-based National Service Frameworks (NSFs) to set out what patients can expect to receive in major care areas or disease groups. NSFs have so far been developed for cancer services and children's intensive care. Others are being developed for diabetes, mental health, services for older people and coronary heart disease.

- Dependable local delivery through systems of clinical governance in local organisations, including mandatory audit.

- Strong monitoring mechanisms: a new statutory Commission for Health Improvement to monitor local systems, offer support where necessary and investigate persistent problems. A Performance Assessment Framework will publish comparative results from different units over a wide range of conditions, and there will be a national survey of NHS patient and user experience.

Though some are sceptical of the government's rhetoric in this field it is to be hoped that these mechanisms will help to reduce the latent errors in the Health Service in the UK. Government expects that serious failures will become uncommon, similar kinds of failure will not recur, incidents in one part of the country will not be repeated elsewhere, systems will be in place to minimise the risk of serious failures happening and less serious incidents will be reported and monitored by a new mandatory national adverse event reporting scheme. Current evidence suggests that much work needs to be done if these expectations are to be realised.

The Government is also addressing the performance of individuals by introducing a system of compulsory annual appraisal, regular review of performance and personal development plans for all doctors working in the Health Service. In England and Wales, where there are doubts or concerns about clinical performance which cannot be resolved locally the employer will be able to refer the doctor to the newly established National Clinical Assessment Authority. If there is a clear and immediate risk to patients, the doctor may be referred to the GMC. Other indications for referral to the GMC include cases where local action has failed or is impractical, or has wider implications.

The number of doctors referred to the GMC has increased dramatically in recent years (fig. 2). The number referred for issues relating to clinical performance has also increased (fig. 3).

\section{References}

1 Leape LL. Error in Medicine. JAMA 1994;272:1851-7. 2 Nightingale F. Notes on Hospitals. London: Longman; 1863.

3 Hatch DJ. GMC Programmes for Reduction of Errors and Protection of Patients. Swiss Med J 2001;82:1344-7.

4 Schimmel EM. The hazards of hospitalization. Ann Intern Med 1964;60:100-10.

5 Steel K, Gertman PM, Crescenzi C, Anderson J. Iatrogenic illness on a general medical service in a university hospital. New Eng J Med 1981;304:638-42.

6 Dearden $\mathrm{CH}$, Rutherford WH. The resuscitation of the severely injured in the accident and emergency department a medical audit. Injury 1985;16:249-52.

7 Bedell SE, Deitz DC, Leeman D, Delbanco TL. Incidence and characteristics of preventable iatrogenic cardiac arrests. JAMA1991;265:2815-20.

8 Brennan TA, Leape LL, Laird N, Hebert L, Localio AR, Lawther AG, et al. Incidence of adverse events and negligence in hospitalized patients: results of the Harvard Medical Practice Study I. New Eng J Med 1991;324:370-6.

9 Wilson RM, Runciman WB, Gibberd RW, Harrison BT, Newby L, Hamilton JD. The Quality in Australian Health Care Study. Med J Aust 1995;163:458-71.

10 Gopher D, Olin M, Donchin Y. The nature and causes of human errors in a medical intensive care unit. Presented at the $33^{\text {rd }}$ meeting of the Human Factors Society; October 18 1989; Denver, Colorado.

11 Reason J. Human Error. Cambridge University Press;1990.

12 Reason J. Managing the Risks of Organisational Accidents. Aldershot: Ashgate; 1997.

13 Perrow C. Normal accidents: living with high-risk technologies. New York: Basic Books; 1984.

14 DeLeval M, Carthey J, Wright D, Farewell V, Reason J. Human Factors and cardiac surgery: a multicentre study. J Thorac Cardiovasc Surg 2000;119:661-72.

15 An Organisation with a Memory. Department of Health. London: HMSO; 2000.

16 A First Class Service: Quality in the New NHS. Department of Health. London: HMSO; 1998. 
Table 1

Intrathecal drug error. An organsational accident chronology in health care:

Death of a patient from maladministration of an anti-cancer drug. Reproduced with permission [15].

\begin{tabular}{|c|c|}
\hline Sequence of events & Failures \\
\hline $\begin{array}{l}\text { A child was a patient in a district general hospital (DGH) } \\
\text { and was due to receive chemotherapy under general } \\
\text { anaesthesia at a specialist centre. He should have been } \\
\text { fasted for } 6 \text { hours before the anaesthetic, but was } \\
\text { allowed to eat and drink before leaving the DGH. }\end{array}$ & $\begin{array}{l}\text { Fasting error. Communications problem } \\
\text { between DGH and specialist centre. }\end{array}$ \\
\hline $\begin{array}{l}\text { No beds were available for the patient on the oncology } \\
\text { ward, so he was admitted to a mixed specialty "outlier" } \\
\text { ward. }\end{array}$ & $\begin{array}{l}\text { Lack of organisational resources (i.e. beds for specialist treatments). } \\
\text { Patient placed in an environment lacking oncology expertise. }\end{array}$ \\
\hline $\begin{array}{l}\text { The patient's notes were lost and not available } \\
\text { to ward staff on admission. }\end{array}$ & Loss of patient information. \\
\hline $\begin{array}{l}\text { The patient was due to receive intravenous vincristine, } \\
\text { to be administered by a specialist nurse on the ward, } \\
\text { and intrathecal (spinal) methotrexate, to be administered } \\
\text { in the operating theatre by an oncology Specialist Registrar. } \\
\text { No oncology nurse specialist was available on the ward. }\end{array}$ & $\begin{array}{l}\text { Communication failure between oncology department } \\
\text { and outlier ward. } \\
\text { Absence of policy and resources to deal with the demands } \\
\text { placed on the system by outlier wards, including shortage } \\
\text { of specialist staff. }\end{array}$ \\
\hline $\begin{array}{l}\text { Vincristine and methotrexate were transported together } \\
\text { to the ward by a housekeeper instead of being kept } \\
\text { separate at all times. }\end{array}$ & $\begin{array}{l}\text { Drug delivery error due to non-compliance with hospital policy, } \\
\text { which was that the drugs must be kept separate at all times. } \\
\text { Communication error. } \\
\text { Outlier wards were not aware of this policy. }\end{array}$ \\
\hline $\begin{array}{l}\text { The housekeeper who took the drugs to the ward } \\
\text { informed staff that both drugs were to go to theatre } \\
\text { with the patient. }\end{array}$ & $\begin{array}{l}\text { Communication error. } \\
\text { Incorrect information communicated. } \\
\text { Poor delivery practice. Allowing drugs to be delivered } \\
\text { to outlier wards by inexperienced staff. }\end{array}$ \\
\hline $\begin{array}{l}\text { The patient was consented only for intrathecal } \\
\text { methotrexate and not for intravenous vincristine. }\end{array}$ & $\begin{array}{l}\text { Poor consenting practice. } \\
\text { Junior doctor allowed to take consent. } \\
\text { Consenting error. }\end{array}$ \\
\hline $\begin{array}{l}\text { A junior doctor abbreviated the route of administration } \\
\text { to IV and IT instead of using the full term in capital letters. }\end{array}$ & Poor prescribing practice. \\
\hline $\begin{array}{l}\text { When the fasting error was discovered, the chemotherapy } \\
\text { procedure was postponed from the morning to the } \\
\text { afternoon list. The doctor who had been due to administer } \\
\text { the intrathecal drug had booked the afternoon off and } \\
\text { assumed that another doctor in charge of the wards that } \\
\text { day would take over. No formal face-to-face handover } \\
\text { was carried out between the two doctors. }\end{array}$ & $\begin{array}{l}\text { Communication failure. } \\
\text { Poor hand-over of task responsibilities. } \\
\text { Inappropriate task delegation. }\end{array}$ \\
\hline $\begin{array}{l}\text { The patient arrived in the anaesthetic room and the } \\
\text { oncology Senior Registrar was called to administer the } \\
\text { chemotherapy. However the doctor was unable to leave } \\
\text { his ward and assured the anaesthetist that he should } \\
\text { go ahead as this was a straightforward procedure. } \\
\text { The oncology Senior Registrar was not aware that } \\
\text { both drugs had been delivered to theatre. The anaesthetist } \\
\text { had the expertise to administer drugs intrathecally but } \\
\text { had never administered chemotherapy. He injected the } \\
\text { methotrexate intravenously and the vincristine into the } \\
\text { patient's spine. Intrathecal injection of vincristine is } \\
\text { almost invariably fatal, and the patient died } 5 \text { days later. }\end{array}$ & $\begin{array}{l}\text { Inadequate protocols regulating the administration } \\
\text { of high toxicity drugs. } \\
\text { Goal conflict between ward and theatre duties. } \\
\text { Poor practice of expecting the doctor to be in two places } \\
\text { at the same time. } \\
\text { Situational awareness error. } \\
\text { Inappropriate task delegation and lack of training. } \\
\text { Poor practice to allow chemotherapy drugs } \\
\text { to be administered by someone with no oncology experience. } \\
\text { Drug administration error. }\end{array}$ \\
\hline
\end{tabular}

